\title{
Condylar position and mandibular function after bilateral sagittal split osteotomy
}

\author{
Hirjak $\mathrm{D}^{1}$, Dvoranova $\mathrm{B}^{1}$, Reyneke $\mathrm{JP}^{2}$, Machon $\mathrm{M}^{3}$, Neff $\mathrm{A}^{4}$ \\ Department of Oral Maxillofacial Surgery, Comenius University, University Hospital Ruzinov, \\ Bratislava, Slovakia. hirjak.dusan@gmail.com
}

\begin{abstract}
AIM: The purpose of this retrospective study was to perform an evaluation of postoperative positional changes of the condyle and mandibular function after bilateral sagittal split osteotomy (BSSO) with manual proximal segment positioning.

PATIENTS: 45 patients were divided into the 2 groups - G1 (advancement - 14 patients) and G2 (setback - 31 patients). Rigid internal fixation screws were utilized in all cases. Inclusion criteria were only BSSO, no TMJ symptoms preoperatively and age 18 or older.

RESULTS: The differences between pre- and postoperative condyle position were evaluated using measurements taken from preoperative CT scans and compared to CT scans made a minimum of 6 months postoperatively. The positional changes in both the axial and sagittal planes were measured and compared. The recovery of mandibular function was evaluated by measuring maximal interincisal opening (MIO). The results revealed that condylar positional changes after BSSO in both groups were minimal and not significantly different for all three dimensions measured. The recovery of mandibular function was faster in the group G2 than in the group G1. Mandibular function reached almost preoperative level in 6-12 months postoperatively in both groups.

CONCLUSION: The results demonstrated that following BSSO, only insignificant condylar displacement and functional changes occurred within 6 to 12 months postoperatively (Tab. 4, Fig. 2, Ref. 47). Text in PDF www.elis.sk.

KEY WORDS: condylar position, bilateral sagittal split osteotomy (BSSO), mandibular function, condylar sag, temporomandibular joint (TMJ) Text in PDF
\end{abstract}

\section{Introduction}

The accuracy of condylar positioning after bilateral sagittal split osteotomy (BSSO) of the mandible influences the postoperative skeletal stability $(1,2,3,4,5,6,7,8,9,10,11,12,13)$. The importance of positioning the condyle correctly in the fossa has been emphasized by an increased use of rigid or semi-rigid fixation $(9,10,11,12,13)$. At surgery, when the condyles are seated properly in its preoperative relation to the glenoid fossa, any postoperative occlusal discrepancies should be corrected by the orthodontist $(9,10,11)$. If the condyles are not seated properly, relapse may occur immediately after an intra-operative removal of the maxillomandibular fixation (MMF), or later $(7,12,13)$.

${ }^{1}$ Department of Oral Maxillofacial Surgery, Comenius University, University Hospital Ruzinov, Bratislava, Slovakia, ${ }^{2}$ Director of The Centre for Orthognathic Surgery, Mediclinic, Cape Town, Department of Oral Maxillofacial Surgery, Faculty of Health Sciences, University of the Western Cape, Cape Town, South Africa, ${ }^{3}$ Department of Oral Maxillofacial Surgery, University Hospital of Charles University, Prague, Czech Republic, and ${ }^{4}$ Department of Oral Maxillofacial Surgery, University Hospital of Marburg, Faculty of Medicine, Philipps University, Marburg, Germany

Address for correspondence: D. Hirjak, MD, PhD, Klinika Department of Oral Maxillofacial Surgery, Comenius University, University Hospital Ruzinov, Ruzinovska 6, SK-826 06 Bratislava, Slovakia.
Intra operative positioning of the mandibular condyles is challenging, however, essentially remains the responsibility of the surgeon. Condylar position may be affected by a direction and amount of mandibular movement, the anatomy of the condyle and glenoid fossa, the anatomy of the mandible, intersegmental interferences, or the type of internal fixation. To avoid unfavourable condylar rotation (peripheral sag), it is important to maintain the bony gap between the proximal and distal segments of the mandible $(11,13,14,15,16)$. Trying to achieve a complete bony contact between the proximal and distal segments using bicortical screws often results in condylar rotation (peripheral sag) and/ or displacement $(11,13,15,16)$. It is well known that alteration in condyle position as the result of orthognathic surgery can not only lead to malocclusion, but to the development of signs and symptoms of temporomandibular disorders (TMD) and condylar resorption as well $(11,14,16)$. For these reasons, several proximal segment positioning devices have been proposed. It remains controversial whether the use of these positioning devices results in a stabile occlusion and better long-term functional outcomes (4, $8,17,18,19,20,21)$. In addition, there has also been some controversial discussion whether rigid (i.e. positional vs lag screws) or rather semi-rigid (i.e. plates and screws) osteosynthesis procedures should be applied for achieving the optimum postoperative position of the condyle within the glenoid fossa $(2,3,5,22,23)$. 
379-385

The aim of this retrospective study was to perform a threedimensional evaluation of postoperative positional changes of the condyle and to assess mandibular function by measuring maximum interincisal opening (MIO) after BSSO using a manual condylar positioning and rigid internal fixation with bicortical positional screws.

\section{Patients and methods}

This retrospective study was approved by the local ethics committee (Ethical committee at University Hospital Ruzinov, Ružinovska 6, Bratislava, Slovakia).

This study consisted of 45 patients, 34 female and 11 male, who underwent BSSO surgery at the Department of Oral Maxillofacial Surgery, Comenius University, University Hospital Ruzinov, Bratislava, Slovakia from January 2015 to December 2017. Patient's age ranged from 18 to 49 years (mean age 30 years). The inclusion criteria for the study were: minimum of 18 years of age, mandibular deformity (Class II or III malocclusion), BSSO surgery only, no TMD symptoms, no prior TMJ surgery, and the availability of preoperative computed tomography (CT) scans and postoperative follow-up CT scans obtained at least 6 months after BSSO.

The patients were divided into the 2 groups. Group 1 (G1) with skeletal Class II malocclusions (14 patients), and Group 2 (G2) with skeletal Class III malocclusions (31 patients). Each group was further divided into 2 subgroups: mandibular symmetry (S) or asymmetry (AS), evaluating the midlines between upper and lower incisors. The amount of advancement of the mandible in G1 $(\mathrm{n}=14)$ ranged from 2 to $9 \mathrm{~mm}$ bilaterally (mean $4.7 \mathrm{~mm})$. Mandibular setback in all the patients of $\mathrm{G} 2(\mathrm{n}=31)$ ranged from 0 to $10 \mathrm{~mm}$ bilaterally (mean $4.3 \mathrm{~mm}$ ). The surgical movements in the G1 and G2 subgroups are demonstrated in the Table 1.

Mandibular function before BSSO was evaluated in all the patients to assure that they were free of TMJ symptoms (sounds, pain, restricted function). Preoperative maximum interincisal opening (MIO) in all the subjects ranged from 32 to $62 \mathrm{~mm}$ (mean 47

Tab. 1. Mandibular distal segment movement (advancement/setback) (measured in millimetres $(\mathrm{mm})$.

\begin{tabular}{|c|c|c|}
\hline \multicolumn{3}{|c|}{ Group of patients: } \\
\hline$\overline{\mathrm{G} 1}$ & 14 patients & advancement from 2-9 mm (mean 4.7) \\
\hline $\mathrm{S}$ & 9 patients & 2-9 mm (mean 5.8) \\
\hline AS & 5 patients & left $2-8 \mathrm{~mm}$ (mean 5.4) right $2-6 \mathrm{~mm}$ (mean 3.0$)$ \\
\hline $\mathrm{G} 2$ & 31 patients & setback from $0-10 \mathrm{~mm}$ (mean 4.3 ) \\
\hline $\mathrm{S}$ & 17 patients & $2-9 \mathrm{~mm}($ mean 4.0$)$ \\
\hline AS & 14 patients & left $2-10 \mathrm{~mm}$ (mean 4.4$)$ right $0-7 \mathrm{~mm}$ (mean 4.4) \\
\hline
\end{tabular}

Tab. 2. Preoperative mandibular function (maximal interincisal opening - MIO) (measured in millimetres ( $\mathrm{mm})$.

\begin{tabular}{|c|c|}
\hline \multicolumn{2}{|c|}{ Group of patients } \\
\hline G1 & 32-49 mm (mean 44.0) \\
\hline $\mathrm{S}$ & 37-49 mm (mean 45.0) \\
\hline AS & $32-45 \mathrm{~mm}($ mean 42.0$)$ \\
\hline G2 & 38-62 mm (mean 51.0) \\
\hline $\mathrm{S}$ & 39-62 mm (mean 52.0) \\
\hline AS & $38-59 \mathrm{~mm}($ mean 50.0$)$ \\
\hline
\end{tabular}

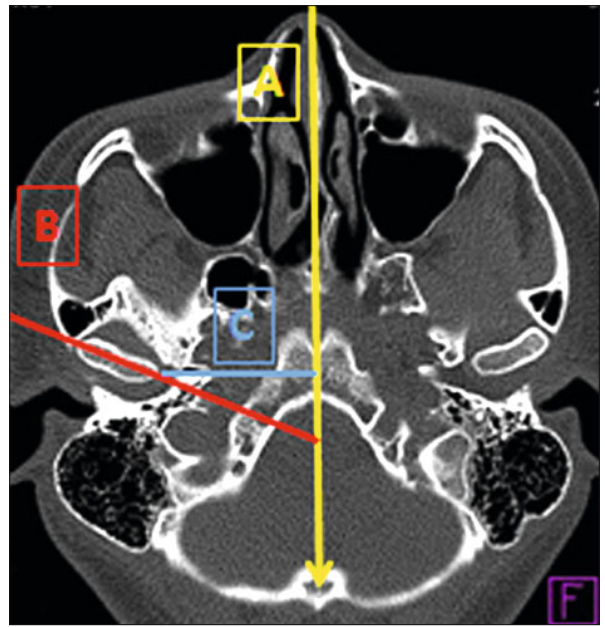

Fig. 1. Evaluation of the condylar position on axial scan images.

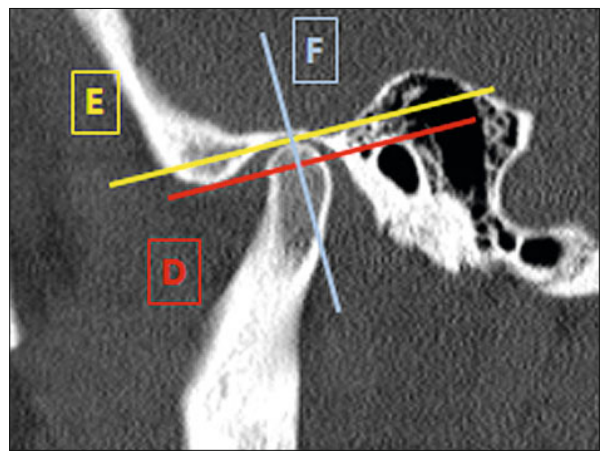

Fig. 2. Evaluation of the condylar position on sagittal scan images.

$\mathrm{mm}$ ). In the group G1, MIO ranged from 32 to $49 \mathrm{~mm}$ (mean 44 $\mathrm{mm}$ ), in the group G2, MIO ranged from 38 to $62 \mathrm{~mm}$ (mean 51 $\mathrm{mm}$ ) (Tab. 2).

\section{Condylar position}

CT images (Somatom Plus 4, Siemens, Germany) were obtained to evaluate preoperative and postoperative condylar position utilizing $1.5 \mathrm{~mm}$ axial and sagittal slices. The images were done 1 to 3 days preoperatively and at minimum 6 months postoperatively (6 to 8 months, mean 7 months).

Applying the measuring methodology proposed by Harris et al (3) and modified by Lee and Park (19), preoperative and postoperative condylar positions were evaluated from the CT scans taken in closed mouth position. The condylar position in glenoid fossa was measured from axial view focused on mediolateral and angular changes. Axial scan image measurements were performed at the level of the greatest mediolateral dimension of the condylar heads. The condylar angulation was determined from the midsagittal line drawn from the base of the vomer to the midpoint of the clivus of the sphenoid (line A), and a line drawn along a condylar axis from the lateral to medial condylar poles (line B). The angular measurement was made between lines $\mathrm{A}$ and $\mathrm{B}$ ( $\mathrm{AB}$ angle). The mediolateral position was measured from the midsagittal line $\mathrm{A}$ to 
the medial pole of the condyle intersecting with a perpendicular line C (CC distance) measured in millimetres on each side (Fig. 1).

Superior-inferior and anterior-posterior changes were measured from sagittal CT scan images chosen from the slices at the midpoint of the condyle. Superior-inferior changes were measured from the distance between line $\mathrm{D}$, drawn from the tip of portion to the inferior surface of the articular eminence, and line E drawn from the superior condylar surface, parallel to line D. The distance between lines D and E (ED distance) was measured in millimetres. Anterior-posterior displacement was measured on line D, measured between portion and intercept point of D and F lines. Line F was drawn from the most superior point of the condyle perpendicular to line D (Fig. 2). The amount of condylar positional change was defined by comparing the preoperative and postoperative condylar measurements (Tab. 4).

\section{Results}

\section{Mandibular function recovery}

Postoperative MIO was measured at 7 days, 1, 3, 6, and 12 months postoperatively. Postoperative mandibular function was restricted during the first 3 months. At 6 months postoperatively, the function was almost at preoperative level in each group. G1 functional recovery lagged behind G2. G1 MIO was lower, when compared to G2 during postoperative period. Measurements revealed a significant restriction of the mandibular function during the first 3 months postoperatively in both groups. At 6 months postoperatively and later, in both groups mandibular function reached the preoperative level.

12 months postoperatively G1 MIO ranged from 31 to 49 millimetres (mean $43.1 \mathrm{~mm}$ ). There were significant differences between G1 (S) and G1 (AS). The final G1 (S) MIO was superior to G1 (AS). G2 MIO ranged from 38 to $64 \mathrm{~mm}$ (mean $48.5 \mathrm{~mm}$ ). There were insignificant differences comparing the subgroups G2 $\mathrm{S} / \mathrm{AS}$ MIO. The final function 12 months postoperatively in all the study groups ranged from 31 to $64 \mathrm{~mm}$ (mean $46.1 \mathrm{~mm}$ ) (Tab. 3).

\section{Evaluation of the condylar position}

Axial scan images

Group G1

Comparison of preoperative and postoperative $\mathrm{CC}$ distance in the group G1 revealed the following results. Paired sample t test revealed no significant differences in $\mathrm{CC}$ distance on left and right sides pre and postoperatively $\mathrm{t}(13)=0.389, \mathrm{p}=0.704$. Despite a symmetric/asymmetric movement of distal segment, there were minimal positional differences at CC postoperatively (Tab. 4).
The measurement of preoperative and postoperative $\mathrm{AB}$ angle in the group G1 and their comparison revealed the following results: Paired sample t test revealed no significant differences on the left side $\mathrm{t}(13)=0.188 ; \mathrm{p}=0.854$, and also on the right side $\mathrm{t}(13)=$ $2.022 ; \mathrm{p}=0.064$. The measured differences showed a slight postoperative inward rotation of right condyles (mean -3.67 degree, $\mathrm{SD}=6.79)$ and also on the left side $(-0.429$ degree, $\mathrm{SD}=8.55)$, as well as no significant difference between the changes on each side $\mathrm{t}(26)=1.111, \mathrm{p}=0.277$ (Tab. 4).

\section{Group G2}

Comparison of preoperative and postoperative $\mathrm{CC}$ distance in the group G2 revealed the following results: Paired sample $t$ test revealed no significance due to surgery for left side $t(30)=0.35, p$ $=0.729$ and for right side $\mathrm{t}(30)=-1.39, \mathrm{p}=0.173$. The measured differences were less than 1.0 millimetre (left side $\mathrm{M}=-0.18$, SD $=2.87$; right side $\mathrm{M}=0.37, \mathrm{SD}=1.46$ ). An independent sample $\mathrm{t}$ test revealed no significance of CC differences after surgery $\mathrm{t}(60)$ $=-0.947), \mathrm{p}=0.347$ (Tab. 4).

Preoperative $\mathrm{AB}$ angle measured on left side ranged from 51.4-88.0 degrees (mean 70.08, $\mathrm{SD}=7.73$ ), on right side ranged from 51.4-87.6 degrees (mean 70.63, $\mathrm{SD}=9.06$ ); postoperative $\mathrm{AB}$ angle on left side ranged from 51.7-81.5 degrees (mean 65.68, $\mathrm{SD}=7.23)$ with significant values after surgery $(\mathrm{t}(30)=3.812, \mathrm{p}$ $=0.001$ ), on right side ranged from 52.0-78.5 (mean 66.59, SD $=6.65)$, the change due to surgery also being significant $(\mathrm{t}(30)$ $=3.265, \mathrm{p}=0.003)$. The measured angles showed a significant slight postoperative inward rotation on both sides, on left side the mean inward rotation was -4.39 degrees $(S D=6.42)$, the right side mean inward rotation was -4.03 degrees $(\mathrm{SD}=6.88)($ Tab. 4$)$.

\section{Sagittal scan images}

Group G1

Preoperative ED distance measured on left side ranged from $-1.05-4.45 \mathrm{~mm}$ (mean 1.31, $\mathrm{SD}=1.40$ ), on right side from 0-3.36 $\mathrm{mm}$ (mean 1.68, $\mathrm{SD}=0.91$ ); postoperative ED distance on left side ranged from $-0.75-4.27 \mathrm{~mm}$ (mean $1.19, \mathrm{SD}=1.58)$, on right side from $-0.5-3.8 \mathrm{~mm}$ (mean $1.71, \mathrm{SD}=1.31$ ) The differences were not significant in paired samples $t$ test on each side (on the left side $\mathrm{t}(13)=400, \mathrm{p}=0.695$ and for right side $\mathrm{t}(13)=-0.177$, $\mathrm{p}=0.862$ ). The vertical measurements revealed postoperative changes less than $1.0 \mathrm{~mm}$ on left side, mean differences were -0.12 $(\mathrm{SD}=1.14)$. On right side, the mean differences were $0.03(\mathrm{SD}=$ $0.69)$, which was not significantly different than the changes on each side $t(26)=-0.434 ; p=0.668$ (Tab. 4 ).

Preoperative FD distance on left side ranged from 8.17-14.8 degrees (mean 11.17, $\mathrm{SD}=2.1$ ), on right side ranged from

Tab. 3. Postoperative mandibular function (maximal interincisal opening - MIO) (measured in millimetres (mm).

\begin{tabular}{|c|c|c|c|c|c|}
\hline Group of patients & 7th day & 1 & 3 & 6 & 12 months \\
\hline G1 & $14-29(20.4)$ & $22-34(27.9)$ & $27-40(34.5)$ & $29-48(38.2)$ & $31-49(43.1)$ \\
\hline $\mathrm{S}$ & $14-29(21.2)$ & $22-34(28.7)$ & $28-40(35.8)$ & $34-47(40.0)$ & $41-49(45.4)$ \\
\hline AS & $16-24(19.6)$ & $22-32(27.2)$ & $27-38(33.2)$ & $29-48(36.4)$ & $31-49(40.8)$ \\
\hline G2 & $10-32(21.3)$ & $19-42(31.8)$ & $20-59(39.1)$ & $23-64(45.1)$ & $38-64(46.1)$ \\
\hline S & $18-28(21.8)$ & $22-42(32.8)$ & $28-59(40.5)$ & $36-64(46.8)$ & $44-64(49.8)$ \\
\hline AS & $10-32(20.9)$ & $19-40(30.8)$ & $20-49(37.7)$ & $23-53(43.4)$ & $38-59(48.5)$ \\
\hline
\end{tabular}


9.71-13.8 degrees (mean 12.1, $\mathrm{SD}=1.35$ ); postoperative FD distance on left side ranged from 8.66-14.3 degrees (mean 10.93, $\mathrm{SD}=1.59$ ), on right side from 7.90-13.1 degrees (mean 11.43, $\mathrm{SD}=1.64)$. There was no significant difference in the change in FD between the pre- and postoperative left side $(\mathrm{t}(13)=0.458, \mathrm{p}$ $=0.655$ and the right side $t(13)=1.354 ; \mathrm{p}=0.199$ ).

Postoperative measurements revealed a slight anterior movement less than $1 \mathrm{~mm}$. On the left side, the mean movement was $0.61 \mathrm{~mm}$; on right side, the mean movement was $0.25 \mathrm{~mm}$.

Postoperative measuring revealed a slight posterior movement less than $1 \mathrm{~mm}$, on left side, the mean movement was $-0.24 \mathrm{~mm}$ $(\mathrm{SD}=1.93)$. On the right side, the mean movement was $-0.63 \mathrm{~mm}$. $\mathrm{SD}=1.73$ ), with no difference in the movement changes between the left and right side $\mathrm{t}(26)=0.563, \mathrm{p}=0.578$ (Tab. 4).

Group 2

Preoperative ED distance on left side ranged from -1.29-3.8 $\mathrm{mm}$, (mean 1.55, $\mathrm{SD}=1.42$ ); on right side from $-0.92-3.58 \mathrm{~mm}$, (mean 1.54, $\mathrm{SD}=1.14$ ), postoperative ED distance on left side ranged from $-1.72-4.33 \mathrm{~mm}$ (mean $1.46, \mathrm{SD}=1.37$ ), on right side from $-1.8-3.4 \mathrm{~mm}$ (mean 1.38), paired samples t test revealed no significant effect of the surgery on left side $\mathrm{t}(30)=0.350), \mathrm{p}=729$.

The vertical measurements revealed minimal less than $1.0 \mathrm{~mm}$ change on the left side $-0.09 \mathrm{~mm}(\mathrm{SD}=0.85)$, on the right side $-0.24 \mathrm{~mm}(\mathrm{SD}=0.93)$. There was no significant positional change postoperatively $\mathrm{t}(60)=-0.947 ; \mathrm{p}=0.347$ (Tab. 4 ).

Preoperative FD distance on left side ranged from 8.5-14.2 $\mathrm{mm}$, (mean 11.2, $\mathrm{SD}=1.53$ ); on the right side from 8.45-14.5 $\mathrm{mm}$, (mean 11.41, SD = 1.49); postoperative FD distance on left side ranged from $9.63-15.5 \mathrm{~mm}$, (mean 11.88, $\mathrm{SD}=1.67$ ), on the right side from 7.92-15.2 mm, (mean 11.73, $\mathrm{SD}=1.91$ ), with a significant impact of surgery on the left side $t(30)=-2.58, \mathrm{p}=$ 0.015 , on the right side the changes were not significant $\mathrm{t}(30)=$ $-1.337, \mathrm{p}=0.191$.

Measuring the pre- and postoperative differences in anteriorposterior position revealed the mean anterior movement of 0.68 $\mathrm{mm}(\mathrm{SD}=1.46)$ on the left side; while on the right side, the mean anterior movement was $0.31 \mathrm{~mm}(\mathrm{SD}=1.31)$. There was no significant difference between FD changes neither on the left nor the right side $\mathrm{t}(60)=1.03, \mathrm{p}=0.307$ (Tab. 4).

\section{Discussion}

Failure to position the condyle accurately in the fossa can result in condylar sag and malposition. Reyneke (11) defined condylar sag as an immediate or late change in position of the condyle in the glenoid fossa after a surgical establishment of a pre-planned occlusion and rigid fixation of the bone fragments leading to a change in the occlusion. Condylar malposition can lead to skeletal relapse, malocclusion, remodelling of condylar head and/or condylar resorption $(1,6,14,20,24,25)$.

Condylar malposition can also lead to TMJ dysfunction and pain. There are many factors affecting postoperative condylar position, such as: anterior, posterior or rotational positioning of the distal segment during surgery, mandibular anatomy, fixation method and the surgeon's experience $(26,27,28,29)$. 
Mandibular osteotomy and repositioning of the distal segment often creates a natural gap between the segments $(3,4,16)$. This gap should be maintained and the segments not forced together $(4,11,13,16)$.

Kang et al (16) suggested that it is important to keep the intersegmental space by using an autogenous bone graft to avoid condylar displacement. Also, it is apparent that the intersegmental space can be maintained by the experienced surgeon without bone graft. Reyneke (11) suggested that condylar relationship to the glenoid fossa is not only critical, but is probably the most demanding step in the BSSO procedure. Reyneke also finds that it is ironic that this is the part of the surgical procedure not visible to the surgeon and that he/she has to rely of "feeling" and experience $(10,11)$.

Harris et al. reported notable changes in condylar position following BSSO. These authors argue that such changes were mainly related to the amount of movement of the distal segment, degree of distal mandibular segment rotation and mandibular shape.

Depending on the underlying preoperative skeletal malocclusion, Neff \& Horch observed considerable postoperative variations in the position of the functional axiographic hinge axis of the condyles compared to the 9-24 months after orthognathic surgery. In Class II individuals, the terminal hinge axis was found in a cranial position 9 and 24 months postoperatively, whereas Class III patients with a mandibular setback demonstrated the hinge axis position inferior and anterior compared to the preoperative reference points.

Verhelst et al (23) stated that the BSSO induced biomechanical stresses at the TMJ. This biomechanical stress can lead to a process frequently called ,physiological joint remodelling“. When joint remodelling surpasses its physiological limits, pathological remodelling can occur regardless of whether the patient had preexisting TMJ dysfunction. The question of why one overloaded joint develops TMD and another develops condylar resorption remains an enigma $(30,31,32,33,34)$. In the same article, the authors state that in the postoperative phase, three types of biomechanical stresses are possible at the TMJ - prolonged alteration of the condyle position, tension in the muscles attached to the mandible, and postoperative orthodontic forces incurred with the use of elastics.

Ochs (24) observed that fixation with 3 bicortical positional screws was 3 times more stable than the use of miniplates and monocortical screws. Murphy et al (25) reported similar results and suggested that 3 bicortical positional screws also had economic advantages over miniplates and monocortical screws.

Kim et al (20) evaluated positional changes of the condyle 12 months in patients following the correction with Class III malocclusion and the factors affecting postsurgical position. In the study, cone beam tomography (CBCT) was performed preoperatively, 2 weeks, 3 months, 6 months and 12 months postoperatively. Condylar rotation in sagittal and coronal planes were evident after 3 and 6 months. However, condylar position was relatively stable after 6 months.

There are a paucity of studies in literature that focuses on the evaluation of postoperative condyle position and mandibu- lar function $(35,36,37,38,39)$. Successful outcomes in terms of mandibular function can be evaluated in different ways, such as by the presence or absence of joint noise, MIO measurement, and mandibular movements with and without pain $(40,41,42,43$, 44). The initial decrease in MIO at $1-6$ months postoperatively is described in most studies $(22,26,27,45,46,47)$. The causes of this finding have been related to a combination of the formation of scar tissue and/or inflammation, as well as new mandibular and TMJ positioning. MIO and mandibular mobility in all excursions was virtually at their preoperative level at 1year follow-up in the present study. Veldhuis et al (26) in their systematic review found no damaging effect of orthognathic surgery on TMJ function. Likewise, the present study demonstrates that BSSO appears to have minimal effect on mandibular function. Patient didn't get any special professional physiotherapy after surgery.

In the present study, for the comparison of the subject's pre and 6 months postoperative CT images, it is important to consider the adaptative and remodelling potential of the condyles. There were insignificant three-dimensional condylar positional changes in both study groups (G1, G2), despite the symmetric and/or asymmetric movements of the distal segments at surgery.

Comparing mandibular function pre and postoperatively, the functional recovery in the group G1 was slower than in the group G2. Despite an acceptable final postoperative mandibular function, there was a decreased MIO in the group G1, when compared to the group G2. The adaptive and regenerative potential of soft and hard TMJ tissues must be considered in this regard as well as the attention to the underlying skeletal malposition and the fundamental alteration of functional geometry of TMJ and mandible after orthognathic surgery.

The results from this study revealed minimal condylar positional changes after BSSO with rigid internal fixation and manual positioning of the proximal fragment. There was no direct correlation between the amount and direction of the mandibular movement and condylar positional changes. Maintaining the intersegmental space is important to minimize postoperative condylar displacement.

In this study, there were insignificant changes detected in all directions of condylar position. Comparing the groups G1 and G2, there were insignificant differences in the postoperative period for functional recovery. Finally, mandibular function reached the preoperative level between 6 and 12 months postoperatively.

Based on this study, the authors conclude that performing BSSO using a manual repositioning and utilizing screw rigid fixation results in minimal condylar displacement. Therefore, the BSSO procedure in the patients without preoperative TMD signs and symptoms appears to be a stable and predictable surgical procedure with a minimal negative effect on TMJ function. Future studies should focus on patients with TMD symptoms before the orthognathic surgery. 


\section{References}

1. Choi BJ et al. Correlation between intraoperative proximal segment rotation and post-sagittal split ramus osteotomy relapse: a three-dimensional cone beam computed tomography study. Internat J Oral Maxillofac Surg 2018; 47 (5): 613-621.

2. Ureturk EU, Apaydin A. Does fixation method affects temporomandibular joints after mandibular advancement? J Cranio-Maxillofac Surg 2018; 46 (6): 923-931.

3. Harris MD, Van Sickels JR, Alder M. Factors influencing condylar position after the bilateral sagittal split osteotomy fixed with bicortical screws. J Oral Maxillofac Surg 1999; 57 (6): 650-654.

4. Tominaga K et al. A simple method for bone positioning of mandibular segments. Internat J Oral Maxillofac Surg 2006; 35 (9): 856-860.

5. Borstlap WA et al. Stabilisation of sagittal split advancement osteotomies with miniplates: a prospective, multicentre study with two-year follow-up: Part I. Clinical parameters. Internat J Oral Maxillofac Surg 2004; 33 (5): 433-441.

6. Xi T et al. 3D analysis of condylar remodelling and skeletal relapse following bilateral sagittal split advancement osteotomies. J Cranio-maxillofac Surg 2015; 43 (4): 462-468.

7. Lee JS, Xi T, Kwon TG. Three-dimensional analysis of mandibular condyle position in patients with deviated mandibular prognathism. Internat J Oral Maxillofac Surg 2017; 46 (8): 1052-1058.

8. Gerressen $\mathbf{M}$ et al. The functional long-term results after bilateral sagittal split osteotomy (BSSO) with and without a condylar positioning device. J Oral Maxillofac Surg 2006; 64 (11): 1624-1630.

9. Tabrizi R et al. Does Fixation Method Affect Stability of Sagittal Split Osteotomy and Condylar Position? J Oral Maxillofac Surg 2017; 75 (12): 2668.e1-2668.e6.

10. Beukes J, Reyneke JP, Becker PJ. Medial pterygoid muscle and stylomandibular ligament: the effects on postoperative stability. Internat Oral Maxillofac Surg 2013; 42 (1): 43-48.

11. Reyneke JP, Ferretti C. Intraoperative diagnosis of condylar sag after bilateral sagittal split ramus osteotomy. Brit J Oral Maxillofac Surg 2002; 40 (4): 285-292.

12. Ohba $\mathrm{S}$ et al. Skeletal stability after sagittal split ramus osteotomy with physiological positioning in patients with skeletal mandibular prognathism and facial asymmetry. Brit J Oral Maxillofac Surg 2016; 54 (8): 920-926.

13. Ellis E. A method to passively align the sagittal ramus osteotomy segments. J Oral Maxillofac Surg 2007; 65 (10): 2125-2130.

14. Arnett CW. Progressive class II development female idiopathic condylar resorption. Oral Maxillofac Surg Clin North Am 1990; (2): 699-716.

15. Hernández-Alfaro $\mathbf{F}$ et al. Three-dimensional analysis of long-term stability after bilateral sagittal split ramus osteotomy fixed with a single miniplate with 4 monocortical screws and 1 bicortical screw: a retrospective 2-center study. J Oral Maxillofac Surg 2017; 75 (5): 1036-1045.

16. Kang MG et al. Postoperative condylar position by sagittal split ramus osteotomy with and without bone graft. J Oral Maxillofac Surg 2010; 68 (9): 2058-2064.

17. Gerressen $M$ et al. Skeletal stability following bilateral sagittal split osteotomy (BSSO) with and without condylar positioning device. J Oral Maxillofac Surg 2007; 65 (7): 1297-1302.
18. Landes CA, Sterz M. Proximal segment positioning in bilateral sagittal split osteotomy: intraoperative controlled positioning by a positioning splint. J Oral Maxillofac Surg 2003; 61 (12): 1423-1431.

19. Lee W, Park JU. Three-dimensional evaluation of positional change of the condyle after mandibular setback by means of bilateral sagittal split ramus osteotomy. Oral Surg Oral Med Oral Pathol Oral Radiol Endodontol 2002; 94 (3): 305-309.

20. Kim YJ et al. Condylar positional changes up to 12 months after bimaxillary surgery for skeletal class III malocclusions. J Oral Maxillofac Surg 2014; 72 (1): 145-156.

21. Helm G, Stepke MTh. Maintenance of the preoperative condyle position in orthognathic surgery. J Cranio-Maxillofac Surg 1997; 25 (1): 34-38.

22. Neff A, Horch HH. Axiographic functional parameters after dysgnathia operations with special reference to the position of the temporomandibular joint. Mund- Kiefer- Gesichtschirurgie 1997; 1 (4): 205-212.

23. Verhelst PJ et al. The Biomechanical Effect of the Sagittal Split Ramus Osteotomy on the Temporomandibular Joint: Current Perspectives on the Remodeling Spectrum. Front Physiol 2019; 10): 1021.

24. Ochs MW. Bicortical screw stabilization of sagittal split osteotomies. J Oral Maxillofac Surg 2003; 61 (12): 1477-1484.

25. Murphy MT, Haug RH, Barber JE. An in vitro comparison of the mechanical characteristics of three sagittal ramus osteotomy fixation techniques. J Oral Maxillofac Surg 1997; 55 (5): 489-494.

26. Te Veldhuis EC et al. The effect of orthognathic surgery on the temporomandibular joint and oral function: a systematic review. Internat Oral Maxillofac Surg 2017; 46 (5): 554-563.

27. Wolford LM, Reiche-Fischel O, Mehra P. Changes in temporomandibular joint dysfunction after orthognathic surgery. J Oral Maxillofac Surg 2003; 61 (6): 655-660.

28. Torro C, Robiony M, Costa S, Sembronio S, Politi M. Conscious analgesia and sedation during orthognathic surgery: Preliminary results of a method of preventing condylar displacement. Brit J Oral Maxillofac Surg 2007; 45: 378-381.

29. Joss CU, Vassallii IM. Stability after Bilateral Sagittal Split Osteotomy Advancement Surgery with Rigid Internal Fixation: A Systemic Review. J Oral Maxillofac Surg 2009; (67): 301-313.

30. Kretscher WB, Baciut G, Baciut M, Sader R. Effect of bimaxillary orthognathic surgery on dysfunction of the temporomandibular joint: retrospective study of 500 consecutive cases. Br J Oral Maxillofac Surg 2019; (57): 734-739.

31. Sebastianii AM, Barato-Filho F, Bonotto D. Influence of orthognathic surgery for symptoms of temporomandibular dysfunction. Oral Surg Oral Med Oral pathol Oral Radiol 2016; 121: 119-125.

32. Togashi M, Kobayashi T, Hasebe D. Effect of surgical orthodontic treatment for dentofacial deformities on sign and symptoms of temporomandibular joint. J Orall Maxillofac Surg Med Pathol 2013; 25: 18-23.

33. Abrahamson C, Henrikson M, Nilner M et al. TMD before and after correction of dentofacial deformities by orthodontic and othognathic treatment. Int J Oral Maxillofac Surg 2013; 42: 752-758.

34. Scolozzi P, Wandeler PA, Courvoisier DS. Can clinical factors predict postoperative temporomandibular disorders in orthognathic patients? A retrospective study of 219 patients. Oral Surg Oral Med Oral Pathol Oral Radiol 2015; 119: 531-538.

35. Kim Y IL, Cho BH, Jung YH, Son WS, Park SB. Cone-beam computerized tomography evaluation of condylar changes and stability fol- 
lowing two-jaw surgery: Le Fort I osteotomy and mandibular setback surgery with rigid fixation. Oral Surg Oral Med Oral Pathol Oral Radiol Endodontol 2011; 115: 681-687.

36. Sonego CL, Scheffer MAR, Chagas Júnior OL, Vetromilla BM et al. In vitro study of a modified sagittal split osteotomy fixation technique of the mandible: a mechanical test. Int J Oral Maxillofac Surg 2018; 47 (10): 1330-1335.

37. Xi T, Van Lui NJ R, Baan F, Schreurs R, de Koning M, Bergé S et al. Three-dimensional analysis of condylar remodeling and skeletal relapse following bimaxillary surgery: A 2-year follow-up study. J CranioMaxillofac Surg 2017; 45 (8): 1311-1318.

38. Gerressen M, Zahed MD, Stockbrink G, Riediger D, Ghassemi A. The Functional Long-Term Results after Bilateral Sagittal Split Osteotomy (BSSO) with and without a Condylar Positioning Device. J Oral Maxillofac Surg 2006; 64 (11): 1624-1630.

39. Kim YJ, Lee Y, Chun YS, Kang N, Kim SJ, Kim M. Condylar positional changes up to 12 months after bimaxillary surgery for skeletal class iii malocclusions. J Oral Maxillofac Surg 2014; 72 (1): 145-156.

40. Peterson LJ, Hwang, Soon-Jung MD, Haers PE et al. Surgical risk factors for condylar resorption after orthognathic surgery. Oral Surg Oral Med Oral Pathol Oral Radiol Endodontol 2000; 89 (5): 542-552.

41. Chen S, Lei J, Wang X, Fu K. Short-Term and Long-Term Changes of Condylar Position After Bilateral Sagittal Split Ramus Osteotomy for Mandibular Advancement in Combination With Le Fort I Osteotomy Evaluated by Cone-Beam Computed Tomography. J Oral Maxillofac Surg 2013; 71 (11): 1956-1966.
42. Kim YK, Yun PY, Ahn JY, Kim JW, Kim SG. Changes in the temporomandibular joint disc position after orthognathic surgery. Oral Surg Oral Med Oral Pathol Oral Radiol Endodontol 2009; 108 (1): 15-21.

43. Xi T, Schreurs R, Van Loon B, De Koning M, Bergé S et al. 3D analysis of condylar remodelling and skeletal relapse following bilateral sagittal split advancement osteotomies. J Cranio-Maxillofac Surg 2015; 43 (4): 462-468.

44. Xi T, De Koning M, Bergé S, Hoppenreijs T, Maal T. The role of mandibular proximal segment rotations on skeletal relapse and condylar remodelling following bilateral sagittal split advancement osteotomies. J Cranio-Maxillofac Surg 2015; 43 (9): 1716-1722.

45. Han JJ, Hwang SJ. Three-dimensional analysis of postoperative returning movement of perioperative condylar displacement after bilateral sagittal split ramus osteotomy for mandibular setback with different fixation methods. J Cranio-Maxillofac Surg 2015; 43 (9): 1918-1925.

46. Lee JS, Xi T, Kwon TG. Three-dimensional analysis of mandibular condyle position in patients with deviated mandibular prognathism. Int $\mathrm{J}$ Oral Maxillofac Surg 2017; 46 (8): 1052-1058.

47. Dreseidler T, Bergman J, Zirk M, Rothamel D, Zoller JE, Kreppel M. Three-dimensional fracture pattern analysis of the Obwegeser and Dal Pont bilateral sagittal split osteotomy. Int J Oral Maxillofac Surg 2016; 45 (11): 1452-1458. 